\title{
Organizational Procedures of the American Meteorological Society
}

\section{Members}

The members of the American Meteorological Society are persons interested in the advancement of the atmospheric and related oceanic and hydrologic sciences and the advancement of their professional applications. They are organized under the Constitution and Bylaws of the Society to actively promote these objectives.

\section{Officers}

The elective officers of the Society are the President, who shall be the immediate past President-Elect, and the President-Elect, whose term of office shall be one year beginning at the close of the Annual Meeting following the election.

The appointed officers of the Society are the Executive Director and the Secretary-Treasurer. Appointment shall require a vote equal to a majority of the entire Council and removal from office shall be by a vote equal to two-thirds of the entire Council.

\section{Council}

The Council is the principal governing body of the Society. It consists of the elective officers, the last two Past Presidents, and 15 other voting members of the society, each elected for a three-year term, with one-third retiring each year. Councilors are eligible for reelection but not to consecutive terms. The Executive Director and Secretary-Treasurer shall be members of the Council ex-officio and without the power to vote.

The Council is in general charge of the affairs of the Society, responsible for ensuring that reasonable actions are taken to accomplish the objectives of the Society outlined above under "Members" and in the Constitution and Bylaws.

The Council meets at the close of the Annual Meeting and when convened by the President, or whenever requested in writing by five or more members of the Council. Eleven Council members eligible to vote constitute a quorum. Unless the Constitution specifically requires a greater proportion, an affirmative vote of a majority, but not less than eight, of the Councilors present is required for the resolution of any question. The Council can transact business by mail, in which case a two-thirds vote of the entire Council eligible to vote is required for an action to take effect.
The Council has established three continuing committees with names, membership, and duties as follows:

\section{The Committee on Public Policy}

a. Membership: The President, who is the Chairman, the President-Elect, the three most recent Past Presidents who are able and willing to serve, and the Chairman of the Scientific and Technological Activities Commission.

b. Special Responsibilities and Authority: to prepare public policy statements to be issued in the name of the Society by the President or an officer designated by him. Public policy statements prepared by the Committee on Public Policy are normally subject to approval by the Council. (Procedures for the issuance of public policy statements are recorded in the Bulletin, 55[2], p. 164-see Bylaws, Article V, 5, I.)

\section{The Committee on Fellows}

a. Membership: Six Fellows of the Society to include at least two members from the "operational and/or private communities," appointed by the President.

b. Responsibilities: To annually prepare a list of nominees for the grade of Fellow for the consideration of the Council.

\section{The Sverdrup Gold Medal Committee}

a. Membership: At least three persons appointed by the President in consultation with the Scripps Institution of Oceanography and the University of Bergen.

b. Special Responsibilities: to recommend the recipient of the Sverdrup Gold Medal award at intervals of not less than two years in recognition of outstanding contributions to knowledge of the physical and dynamical interactions between the oceans and the atmosphere.

\section{Executive Committee}

The Executive Committee is composed of the President, who shall be the Chairman, the President-Elect, who shall be the Vice-Chairman, the two most immediate Past Presidents, and two additional members of the Council other than 
those named above, who shall be elected by majority vote of the Council, one each year for a term of two years. The Executive Director and Secretary-Treasurer, both ex-officio and without power to vote, also shall be members of the Executive Committee. It is the executive arm of the Council, reporting to the Council and conducting the affairs of the Society within the limits of the powers conferred on it by the Council.

The Executive Committee meets as often as it deems necessary. A majority of voting members, at least one of whom shall be the President or President-Elect, shall constitute a quorum. An affirmative vote of a majority of the members present, at least one of whom shall be the President or President-Elect, shall be required for the resolution of any question.

The Executive Committee has established six continuing committees reporting to the Executive Committee, with names, membership, and duties as follows:

1. Admissions Committee-comprising not less than five members to be nominated by the President and concurred in by the Executive Committee, to hold office for five years and not to be immediately eligible for reappointment.

Duty: To be responsible for recommending applicants to the Executive Committee applicants for membership of every class except Honorary and Fellow.

2. Awards Committee - comprising not less than three members to be nominated by the President and concurred in by the Executive Committee, to hold office for one year and to be eligible for reappointment.

Duty: To be responsible for recommending persons to the Executive Committee to be accorded the various awards, honors and distinctions under the aegis of the Society except where another method of nomination is explicitly required in the terms of the award.

3. Nominating Committee-comprising not less than three members to be nominated by the President and concurred in by the Executive Committee, to hold office for one year and to be eligible for reappointment.

Duty: To be responsible for passing a slate of nominees for elective Officers and Councilors of the Society to the Secretary-Treasurer.

4. Committee on the History of the Atmospheric Sciencescomprising not less than three members to be nominated by the President and concurred in by the Executive Committee, and to hold office at the pleasure of the President.

Duty: To define procedures for a systematic historical survey of the atmospheric sciences.

5. Investment Committee-comprising four members to be nominated by the President and concurred in by the
Executive Committee, and to hold office for a term of four years with one member's term expiring at the end of each Annual Business Meeting and with a second term being permitted. In addition, the President, Executive Director, Secretary-Treasurer, and Chairman of the Planning Commission are ex-officio members.

Duty: As a policy committee, to provide advice to the Executive Committee, Secretary-Treasurer, and any investment counsel that may be retained, in investment matters. The Committee's primary concerns will not be those of portfolio management; rather, it will be concerned primarily with such matters as articulation of the Society's investment objectives, the general risk level to be assumed, the balance of equities and debt instruments in the portfolio, the maturity spectrum of debt instruments in the portfolio, and the quality of portfolio management.

6. Appeals Committee-comprising three members to be appointed by the President with the concurrence of the Chairman of the Commission on Professional Affairs and the Executive Director.

Duty: To hear appeals on denial of the Certified Consulting Meteorologist certificate, the Seal of Approval, membership status, and other matters as determined by the Executive Committee.

\section{Executive Director}

The Executive Director is the head of the permanent staff of the Society, reports to the Executive Committee, and shall have such powers and duties as are provided in the Constitution and Bylaws.

The Executive Director is appointed by the Council on the recommendation of the Executive Committee and holds office at the pleasure of the Council.

The Executive Director is responsible to the Executive Committee for the continuing management of the organization in all aspects except as specifically reserved by the Executive Committee or the Council.

\section{Secretary-Treasurer}

The Secretary-Treasurer shall have such powers and duties as are provided in the Constitution and Bylaws.

\section{Commissions}

The Commissions are the principal operating bodies of the Society in fields other than those delegated to the Executive Committee.

The Commissions will consist of a chairman, appointed 
by the Council on the recommendation of the President for a period not exceeding three years; reappointment for a second three-year term is permissible, but not a third. Members are appointed in the manner outlined in the details below. The appointments of chairmen will be staggered at the discretion of the Executive Committee.

A majority of the members of a Commission, constituent Board, or Committee will constitute a quorum unless otherwise stated.

\section{Authority and Responsibilities:}

1. The Commissions will report directly to the Council but will coordinate with the Executive Committee between the Council sessions, and they will provide advance copies of their reports to the Executive Committee so that the financial consequences can be assessed in advance of the Council's consideration.

2. Each Commission will report on its activities and requirements in writing to the Council at least annually.

3. The chairmen of the Commissions are entitled to participate in Council meetings, without vote unless duly elected to the Council.

4. The Commissions may appoint ad hoc committees for specific purposes from time to time.

5. Each Commission will establish Boards and Committees as outlined herein.

6. Five Commissions have been established with the following names, membership, special authority and responsibilities.

\section{a. Commission on Professional Affairs}

\section{i. Membership:}

- a chairman

- the chairmen of the constituent Boards

ii. Special Responsibilities and Authority: to have final authority on granting Seals of Approval for Weathercasting, both for radio and television, and on granting Certifications for Consulting Meteorologists, except those cases where ethics are involved shall be referred to the Council, and those cases where appeals of denials of certification as CCM or of Seals of Approval shall be referred to the Executive Committee.

The Commission shall establish the following Boards:

- Certified Consulting Meteorologists

- Broadcast Meteorology

- Private Sector Meteorology

- Operational Government Meteorologists with membership, responsibilities, and terms for all board appointments as outlined herein. An appointee who has served for a full term may not be immediately reappointed to the same board.

\section{b. Publications Commission}

\section{i. Membership:}

- a chairman

- the Chief Editors of the Society's periodicals and serials

- the chairmen of the publication boards, if not included under the preceding

- three members-at-large appointed by the Council on the recommendation of the President, each for a three-year term, one term expiring each year (the purpose of these three membersat-large is to ensure a measure of representation by disciplines)

ii. Special Responsibilities and Authority: to be responsible to the Council for the general publication program of the Society and specifically for the Journal of the Atmospheric Sciences, the Journal of Applied Meteorology, the Journal of Physical Oceanography, the Monthly Weather Review, the Journal of Atmospheric and Oceanic Technology, Weather and Forecasting, the Journal of Climate, Meteorological and Geoastrophysical Abstracts, and Meteorological Monographs, and to advise the Executive Director on the nature of the Bulletin visa-vis these other publications.

The Commission shall establish:

- Board of the Journal of the Atmospheric Sciences

- Board of the Journal of Applied Meteorology

- Board of the Journal of Physical Oceanography

- Board of the Monthly Weather Review

- Board of the Journal of Atmospheric and Oceanic Technology

- Board of Weather and Forecasting

- Board of the Journal of Climate

- Board of Meteorological and Geoastrophysical Abstracts

- Board of Meteorological Monographs

with membership, responsibilities, and authorities as outlined herein.

\section{c. Education and Manpower Commission}

\section{i. Membership:}

- a chairman

- the chairmen of the three constituent Boards

Any two members including the chairman of the Commission will constitute a quorum. 
ii. Special Responsibilities: to be responsible to the Council for the educational program of the Society, and to recommend recipients of the Macelwane Awards, the Howard T. Orville Scholarship, and the Howard H. Hanks, Jr., Scholarship to the Council on the basis of the recommendations by a Committee of Judges for Undergraduate Awards appointed by the Commission. The Commission shall establish:

- Board of Meteorological and Oceanographic Education in Universities

- Board of School and Popular Meteorological and Oceanographic Education

- Board on Women and Minorities

The Committee of Judges for Undergraduate Awards is a Committee of the Education and Human Resource Commission.

Special Responsibilities: to recommend the annual recipients of first and/or second and/or third place in the Father James B. Macelwane Awards on the basis of essays submitted by undergraduate students and to recommend the annual recipient of the Howard T. Orville Scholarship and the Howard H. Hanks, Jr., Scholarship.

\section{Policies:}

1) The Orville and Hanks Scholarships will be awarded to students entering their final undergraduate year.

The awarding of the scholarships in meteorology shall be based on academic excellence and achievement. To be eligible for the award, on the final date of receipt of nominations the candidate must

a) be an undergraduate major in a meteorology department or other department actively engaged in work on some aspects of atmospheric science; and

b) intend to make atmospheric sciences his career.

The candidate must be nominated by his major department. His nomination must be supported by a letter of recommendation from the department chairman or other designated department member, reflecting the overall view of the department faculty.

2) The annual Father James B. Macelwane Awards have been established to encourage original student papers concerned with some phase of the atmospheric sciences. All registered undergraduate students of a college or university in the Americas are eligible to participate, except that no more than two students from any one institution may enter a paper.

Deadline for nominations shall be set by the Committee. The winners shall be announced at the Annual Meeting.

\section{Procedures:}

1) The Committee of Judges for Undergraduate Awards shall have final responsibility for recommending the recipients.

2) Headquarters of the Society shall handle all publicity, preparation and distribution of application forms, collection of applications, and distribution to the Judges.

\section{d. Scientific and Technological Activities Commission}

\section{i. Membership:}

- a chairman

- the chairmen of the scientific and technological activities committees of the Society

A total of five members will constitute a quorum.

ii. Special Responsibilities: to keep watch on the progress of research and operations and to inform the Council of lack of support where support seems to be needed and of cases where important projects are in jeopardy for lack of funds; to be responsible to the Council for receiving and reviewing the reports of the scientific and technological committees and extracting therefrom those items on which the Council should take action and to transmit these to the Council with their recommendations (the original committee reports shall be forwarded to the Council for information); to recommend to the Council the establishment of new committees or the dissolution of those no longer serving a useful purpose; to establish and review the terms of reference of the committees. Scientific and technological activities committees will be established by the Council on the recommendation of the Scientific and Technological Activities Commission to coordinate opinion and stimulate activity in any scientific or technological subject of interest to the Society.

The Scientific and Technological Activities Commission will appoint the chairmen and members of the committees subject to the concurrence of the Council expost facto. Terms of appointment are for two to three years as determined by the Commissioner with the privilege of reappointment for a period up to three years.

Each committee will report at least annually to the Commission; each committee within its as- 
signed field is responsible for a continuous review of the Society's general activities and for making such recommendations as appear desirable to ensure that the activity of the Society reflects the importance of and interest in the field of the committee.

\section{e. Planning Commission}

The Planning Commission shall be responsible to the Council for long-range planning and related recommendations to ensure that the Society anticipates the changing needs of the members and that the organizational and fiscal policies of the Society are commensurate with the role of the Society.

\section{i. Membership:}

- a chairman

- the last two Past Presidents

- four members appointed by the Council, each to hold office for four years, one changing each year

Any four members including the chairman will constitute a quorum.

ii. Special Responsibilities and Authorities: to study and report on any planning problem referred to it by the Council, consulting other Commissions as necessary; to initiate studies on any planning problem that appears to the Commission to require attention and to report its findings to the Council; to study and report to the Executive Committee on any planning item that the Executive Committee may refer to it.

\section{Boards}

The principal operating components of certain Commissions shall be known as Boards.

- Membership: The chairmen and members of Boards will be appointed by the Council on the recommendation of the responsible Commission.

- Term of Office: The terms of office for the chairman and members of a Board shall be established by the responsible Commission with the concurrence of the Council, having due regard for the need of continuity on the one hand and for the desirability of the maximum membership participation on the other.

- Quorum: A majority of the members of a Board, including the chairman, shall constitute a quorum.

- Reports: Each Board shall report at least annually to its Commission.

- ad hoc Committees: A Board may establish ad hoc committees from time to time to deal with specific problems.
1. Responsibilities, Authorities, and Terms of Office: The following generalized responsibilities, authorities, and terms of office outline the general field of each Board. Specific direction or amplification of these may be issued by the Council through the responsible Commission or by the Commission from time to time.

a. Board of Certified Consulting Meteorologists: to evaluate educational requirements and standards, professional competence, professional level, and reputation of all applicants for certification by the Society, and to make recommendations for approval or rejection of applicants for certification to the Executive Committee. To consist of five members, one appointed each year for a term of five years.

b. Board of Broadcast Meteorology: to recommend to the Commission, in recognition of competence in weathercasting, those applicants for the Seal of Approval of the Society whose performance and program have met the specific criteria of informational value, audience interest, educational value, and professional attitude, and to nominate recipients for the Society's Annual Award for Outstanding Service by a Broadcast Meteorologist. To consist of seven members, two appointed each year except three each third year, each for a term of three years.

c. Board on Private Sector Meteorology: to stimulate activity on matters pertaining to the practice of private meteorology, and keep the Commission on Professional Affairs advised of these actions; to provide consultation to other Boards and Committees on such matters; to evaluate legislation and government practices affecting private meteorology and develop pertinent policy positions for consideration by this Commission; to encourage the increased use of meteorological information by industry and business; and to nominate recipients for the Society's annual Award for Outstanding Contribution to the Advance of Applied Meteorology. To consist of six members, two appointed each year, each for a term of three years.

d. Board for Operational Government Meteorologists: to serve the needs of weather forecasters and others in the government weather services to the extent consistent with the objectives of the Society. To consist of six members, two appointed each year, each for a term of three years.

e. Board of the Journal of Atmospheric Sciences: to act as scientific editor(s) of the Journal and appoint referees; to determine editorial policy for the Journal within the limits set by the Commission; to encourage the submission of papers over the full scientific range embraced by the Journal; and to encourage the submission of papers from outside North America. The Chief Editor of the Journal serves as Chairman and is appointed for a three-year term, which may be renewed for an additional period of two years. 
f. Board of the Journal of Applied Meteorology: to act as scientific editor(s) of the Journal and appoint referees; to determine editorial policy for the Journal within the limits set by the Commission; to encourage the submission of papers over the full scientific range embraced by the Journal; and to encourage the submission of papers from outside North America. The Chief Editor of the Journal serves as Chairman and is appointed for a three-year term, which may be renewed for an additional period of two years.

g. Board of the Journal of Physical Oceanography: to act as scientific editor(s) of the Journal and appoint referees; to determine editorial policy for the Journal within the limits set by the Commission; to encourage the submission of papers over the full scientific range embraced by the Journal; and to encourage the submission of papers from outside North America. The Chief Editor of the Journal serves as Chairman and is appointed for a three-year term, which may be renewed for an additional period of two years.

h. Board of the Monthly Weather Review: to act as scientific editor(s) of the Journal and appoint referees; to determine editorial policy for the Journal within the limits set by the Commission; to encourage the submission of papers over the full scientific range embraced by the Journal; and to encourage the submission of papers from outside North America. The Chief Editor of the Journal serves as Chairman and is appointed for a three-year term, which may be renewed for an additional period of two years.

i. Board of the Journal of Atmospheric and Oceanic Technology: to act as scientific editor(s) of the Journal and appoint referees;to determine editorial policy for the Journal within the limits set by the Commission; to encourage the submission of papers over the full scientific range embraced by the Journal; and to encourage the submission of papers from outside North America. The Chief Editor of the Journal serves as Chairman and is appointed for a three-year term, which may be renewed for an additional period of two years.

j. Board of Weather and Forecasting: to act as scientific editor(s) of the Journal and appoint referees; to determine editorial policy for the Journal within the limits set by the Commission; to encourage the submission of papers over the full scientific range embraced by the Journal; and encourage the submission of papers from outside North America. The Chief Editor of the Journal serves as Chairman and is appointed for a three-year term, which may be renewed for an additional period of two years.

k. Board of the Journal of Climate: to act as scientific editor(s) of the Journal and appoint referees; to determine editorial policy for the Journal within the limits set by the Commission; to encourage the submission of papers over the full scientific range embraced by the Journal; and to encourage the submission of papers from outside North America. The Chief Editor of the Journal serves as Chairman and is appointed for a three-year term, which may be renewed for an additional period of two years.

1. Board of Meteorological and Geoastrophysical Abstracts: to advise the Editor on the choice of special subjects, and of new sources of information to ensure adequate coverage at all times; and to advise the Editor on matters of policy within the limits set by the Commission.

m. Board of Meteorological Monographs: to determine the subjects to be covered in the monograph series and, if necessary, solicit authors to participate; to act as scientific editor(s) of the Monographs; to determine editorial policy with respect to the Monographs within the limits set by the Commission; and to exercise similar editorial functions with respect to any special publications of the Society that might be referred to it by the commission from time to time. The Editor of MeteorologicalMonographsserves as Chairman, and is appointed for a five-year term, renewable for one additional term of five years.

n. Board of School and Popular Meteorological and Oceanographic Education: to be responsible for organizing and promoting an aggressive program for meteorological education in the schools in the United States designed to increase the level of the appreciation of the importance of meteorology in everyday life by both the teacher and the student, and to be concerned with films, exhibits, pamphlets, and other materials for the general public.

o. Board of Meteorological and Oceanographic Education in Universities: to be aware of the current standards of teaching in meteorology in the United States; to promote the teaching of meteorology at the undergraduate level to those whose primary studies are in fields in which the weather plays an important part (e.g., agriculture, forestry, etc.); and to promote the teaching of meteorology at the full professional level to increase the supply of competent meteorologists with advanced degrees for operations and research.

p. Board on Women and Minorities: to develop AMS programs to increase the participation and numbers of women and minorities in the professions embraced by the Society by opening up educational and professional opportunities to women and minorities in the professions embraced by establishing role models for persons seeking careers in the profession, and by informing the members of the Society and other appropriate organizations of the need for affirmative action. 


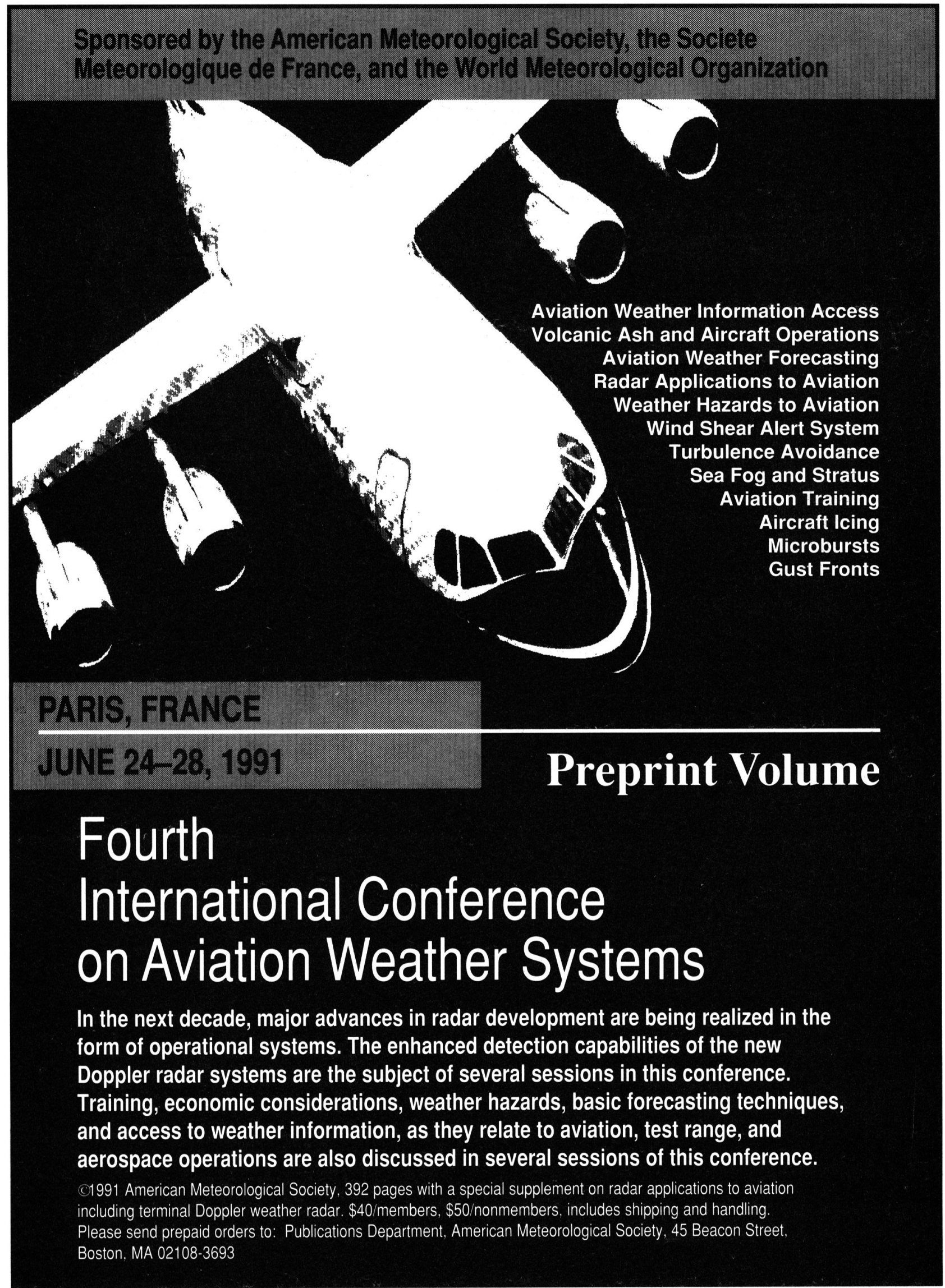




\section{TH CONFERENCE ON}

HURRICANES AND

NEW FROM THE

AMERICAN METEOROLOGICAL SOCIETY

\section{TROPICAL METEOROLOGY}

MAY 6-10,
1991
MIAMI,
FLORIDA

\section{PREPRINTS}
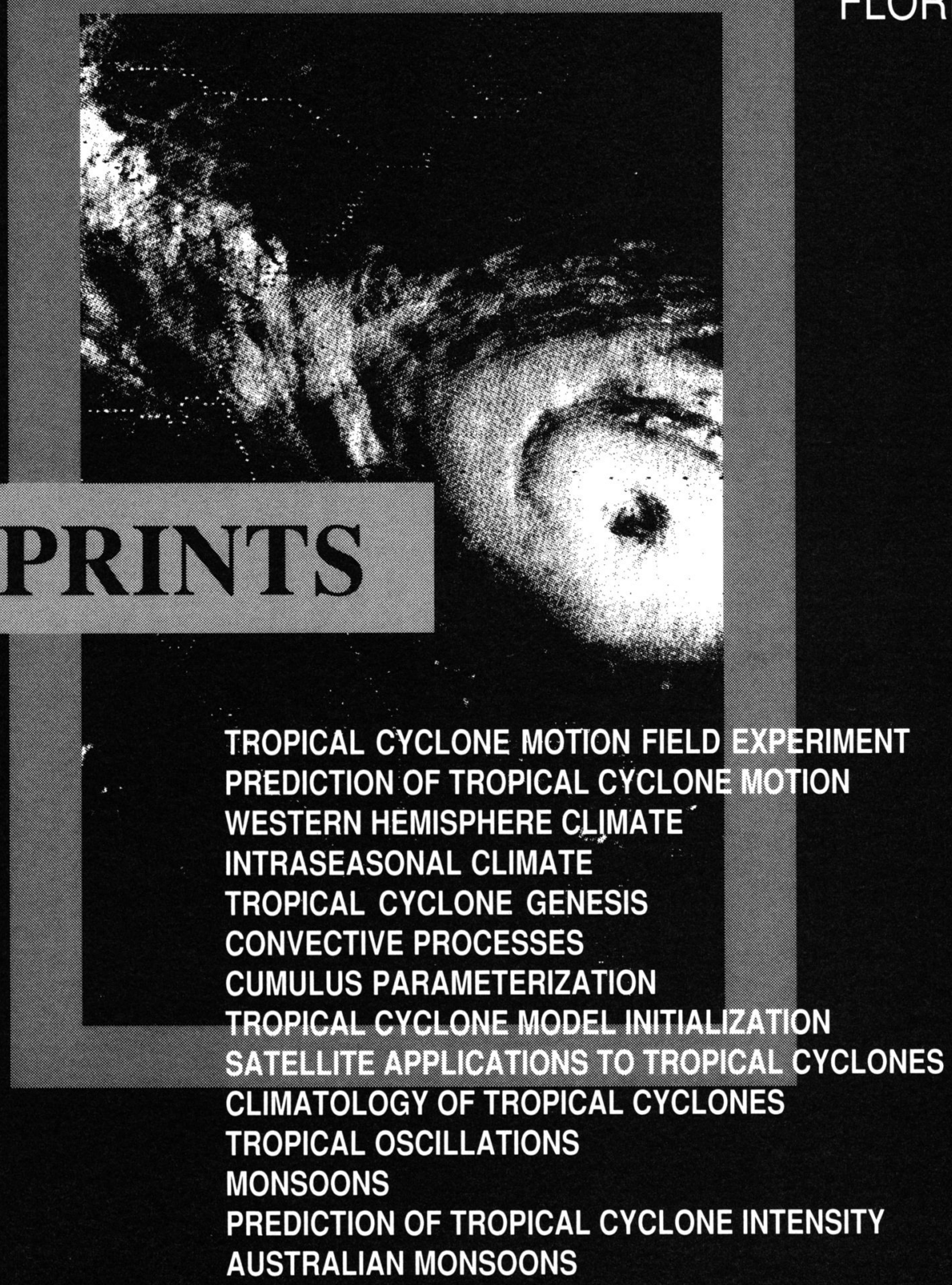

C1991, paperbound, 588pp, complete with B8W illustrations, charts, and graphs. $\$ 33 /$ members, $\$ 43 /$ list, including shipping and handling. Please send prepaid orders to: Publications Department, American Meteorological Society, 45 Beacon Street, Boston, MA 02108. 